\title{
Mechano-signaling in heart failure
}

\author{
Byambajav Buyandelger • Catherine Mansfield • Ralph Knöll
}

Received: 20 December 2013 /Revised: 29 January 2014 / Accepted: 30 January 2014 / Published online: 16 February 2014

(C) The Author(s) 2014. This article is published with open access at Springerlink.com

\begin{abstract}
Mechanosensation and mechanotransduction are fundamental aspects of biology, but the link between physical stimuli and biological responses remains not well understood. The perception of mechanical stimuli, their conversion into biochemical signals, and the transmission of these signals are particularly important for dynamic organs such as the heart. Various concepts have been introduced to explain mechanosensation at the molecular level, including effects on signalosomes, tensegrity, or direct activation (or inactivation) of enzymes. Striated muscles, including cardiac myocytes, differ from other cells in that they contain sarcomeres which are essential for the generation of forces and which play additional roles in mechanosensation. The majority of cardiomyopathy causing candidate genes encode structural proteins among which titin probably is the most important one. Due to its elastic elements, titin is a length sensor and also plays a role as a tension sensor (i.e., stress sensation). The recent discovery of titin mutations being a major cause of dilated cardiomyopathy (DCM) also underpins the importance of mechanosensation and mechanotransduction in the pathogenesis of heart failure. Here, we focus on sarcomere-related mechanisms, discuss recent findings, and provide a link to cardiomyopathy and associated heart failure.
\end{abstract}

Keywords Mechanosensation · Mechanotransduction · Mechanoelectric feedback · Electromechanic feedback · Heart failure

This article is published as part of the Special Issue on Heart Failure.

Byambajav Buyandelger and Catherine Mansfield contributed equally to this work.

B. Buyandelger $\cdot$ C. Mansfield $\cdot$ R. Knöll $(\bowtie)$

Imperial College, British Heart Foundation - Centre for Research

Excellence, National Heart and Lung Institute, Imperial Centre for

Translational and Experimental Medicine, Hammersmith Campus,

Du Cane Road, London W12 0NN, UK

e-mail: r.knoell@imperial.ac.uk

\section{Introduction}

Mechanosensation is a fundamental process in biology [23] and particularly important for the heart [17]. However, mechanosensation is a broadly applied term with no clear definition in the biological sciences. There are different types of mechanical stimuli and it is important to differentiate between them. Stress $(\sigma)$ (dimension: newton per square meter) is physically defined by:

$\sigma=\frac{F}{A}$

where $F$ is the applied force per unit area $(A)$. Also, "shear stress" $(\tau)$ (dimension: newton per square meter), where the applied force $(F(S)=$ shear force) acts parallel to the area $(A)$, is shown as:

$\tau=\frac{F(S)}{A}$

Other types of physical stresses such as compression and torsion may also occur and are equally important. Distinct from stress is "strain" ( $\varepsilon$ ) (dimensionless) which is physically defined by:

$\varepsilon=\frac{\Delta L}{L_{0}}$

where $L_{0}$ is the initial length and $\Delta L$ is the change in length. Another important parameter is Young's modulus (dimension: newton per square meter), which is a measure of the stiffness:

$E=\frac{\sigma}{\varepsilon}$ 
Cells are able to detect stress and strain via changes in conformation of proteins or macromolecular protein complexes, but the precise molecular mechanisms remain unclear. In this regard, two different models have been developed to explain mechanosensory behavior (Table 1): (1) the localized and (2) the decentralized model. The localized model proposes that changes at the cell membrane are sensed immediately and are transmitted from there to other parts of the cell. In contrast, the decentralized model proposes that any force applied at the cell surface will cause deformations of elastic cytoskeletal components and, as such, can be sensed far away from the area of impact. The latter model is also called the "tensegrity" model (derived from tensional integrity) based on Buckminster Fuller's geodesic dome.

The concept of tensegrity has profound consequences for cell biology as it implies that nearly every protein is involved in mechanosensation and mechanotransduction. Therefore, naturally occurring mutations in these components or complete loss of these components such as those observed in mouse knockout studies are all expected to affect mechanosensory functions.

Different mechanosensory protein complexes can be found in cardiac myocytes: (1) cell membrane associated, (2) intracellular embedded, and (3) sarcomere related (Table 1). All these various signalosomes are sensitive to different types of mechanical stimuli. For example, a deformation of the cell membrane may be detected by cell membrane-associated signalosomes, such as stretch-activated channels, angiotensin receptors, the caveolae, and integrin-mediated signaling. Depending on severity and duration, these events may also be sensed by intermediate filaments and/or by sarcomereassociated signalosomes. Here, we focus on mechanical stimuli and try to put them into a physiological perspective (please see [29] for a recent review on hormonal stimulators of hypertrophy).

Table 1 Summary of the localized and decentralized models of cardiac mechanosensation

\begin{tabular}{lc}
\hline $\begin{array}{l}\text { Localized } \\
\text { mechanosensation }\end{array}$ & $\begin{array}{l}\text { Decentralized mechanosensation } \\
\text { (tensegrity) }\end{array}$ \\
\hline Mechanosensitive ion channels & Sarcomere related signaling: \\
Transmembrane receptors & Z-disc titin/MLP/telethonin \\
\multicolumn{1}{l}{ Integrins/dystrophin } & Titin kinase/MURF1 and 2/nbr1/p62 \\
Angiotensin receptor & I-band titin/FHL1/ERK/MARP \\
Caveolae & Actomyosin interaction \\
& Protein-protein interaction-mediated \\
& processes: \\
& Kinases (MAPK) \\
& Phosphatases (calcineurin) \\
& Other posttranslational modifications \\
\end{tabular}

\section{Heart failure, hypertrophy, and mechanical forces}

Heart failure is the leading cause of death worldwide [26]. While we continue to unravel the genetic basis of heart failure and while the equilibrium between cardiomyocyte loss and regeneration is severely damaged in heart failure, the functional link between both and how mechanical forces influence these events remain not well understood [33]. This fact is underscored by the recent discovery that the frequency of potential heart failure causing mutations is much higher than the prevalence of heart failure itself [14]. It might well be that the magnitude of mechanical forces combined with genetic defects in mechanosensation or mechanotransduction triggers pathological effects and disease. Cardiac hypertrophy (or remodeling [19]) and its reverse, cardiac atrophy, are triggered, among others, by an increase or decrease in physical stress, respectively. At the organ level, these changes lead to significant remodeling processes, including changes in angiogenesis and the composition of the extracellular matrix [19].

At the cellular level, cardiac hypertrophy and atrophy are associated with an increase or decrease in cell size, respectively, which alone poses a tremendous challenge for every cell. These changes are particularly important for cardiac myocytes not only because new sarcomeres have to be added in parallel (during pressure overload) or in series (during volume overload) or they have to be removed in atrophy which can be described as remodeling in three dimensions. However, membrane constituents have to increase or decrease proportionately which can be described as remodeling in two dimensions. Due to transcription factors being unable to separately regulate single genes (i.e., there are no specific sets of transcription factors available to separately regulate the transcription of membrane or cellular components), membrane and cellular components have to change proportionately and a new equilibrium has to be found, which is only possible within certain limits. Therefore, it is no surprise that lethality after myocardial infarction is highest immediately in the days after the incident where remodeling occurs [44]. Interestingly, these arrhythmias can be efficiently terminated by overexpression of a dominant negative mechanosensitive $\mathrm{KCNH} 2$ channel (KCNH2-G628S) or by application of the $\mathrm{KCNH} 2$ channel blocker dofetilide [1]. This result is interesting because ischemia/reperfusion is associated with changes in the expression of a multitude of mechanosensitive channels such as TRPC6 [24] (please see for a brief review: [47]). Moreover, stretch is known to have a preconditioning effect on ischemia/ reperfusion [39] which is sensitive to the inhibition of $\mathrm{K}_{\mathrm{ATP}}$ channels [36]; therefore, interference with $\mathrm{KCNH} 2$ could have a negative impact on cell survival. TRPC6 is regulated by the calcineurin/nuclear factor of activated T cells (NFAT) pathway [24] and negatively regulates endothelin which leads to antifibrotic effects - a hallmark of physiological hypertrophy [29]. Also, overexpression of calcineurin has protective 
effects in a murine model of dilated cardiomyopathy (DCM) [13]. While calcineurin/NFAT signaling is largely seen as an inductor of pathological hypertrophy, this pathway can also play a role in physiological hypertrophy.

Therefore, we argue that no signal transduction pathway is adaptive or maladaptive, rather the strength of the stimulus, its nature (i.e., persistent such as in aortic constriction or intermittent such as during exercise), and the genetic composition of the organism will decide if the stimulus results in heart failure. Although models have been reported whereby hypertrophy was not necessary to sustain elevated biomechanical stress [7], hypertrophy, within limits and if reversible, is initially beneficial. From a signaling point of view, hypertrophy is expected to prolong, while atrophy is expected to shorten signal transduction from the cell membrane to the nucleus.

\section{Sarcomere-related mechanisms of mechanosensation}

In contrast to other cell types, striated muscle cells are unique in that their primary function is to generate forces which enable the circulation of blood or movement of the body. These forces need to be "fine-tuned" and carefully controlled which may be defined as "sensing of the magnitude and dynamics of contractility," as opposed to the well-known concepts of the "perception of extracellular mechanical stimuli" - a general description of mechanosensation which can be found in every living cell [22]. From this point of view, it is therefore not surprising that several mechanosensitive signalosomes are present in sarcomeres (Fig. 1).

During the course of the last decade, much attention has been focused on the passive elastic components of the sarcomere as mechanosensors, particularly the giant proteins titin, nebulin (nebulette in the heart), and obscurin [29]. However, Z-disc-related mechanosensation remains not well understood. The Z-disc is made up of a lattice of $\alpha$-actinin molecules, which anchor the ends of actin filaments, and thus transmits force from the molecular motor to adjacent sarcomeres and ultimately to the ends of the contractile cell. Apart from transmitting forces to the ends of the cell, each Z-disc is also connected to the extracellular matrix (ECM). Hence, force transmission to the cavity of the heart also, and maybe predominantly, occurs via the Z-disc-integrin-ECM mechanical pathway. The Z-disc is flexible and muscle shortening, which causes high systolic wall stress, changes the conformation of the $\alpha$-actinin lattice. This may enable sensation of tension $(\sigma=F / A)$, which may involve a signalosome consisting of muscle LIM protein (MLP, CSRP3), telethonin (TCAP), and the amino-terminal titin [18]. Loss of MLP in genetically altered animals or MLP mutations in humans are associated with various types of cardiomyopathy and associated heart failure. For example, the $10 \mathrm{~T} \rightarrow \mathrm{C}$ (Trp4Arg) MLP missense mutation has been identified in several cardiomyopathy patients and is present at high frequencies (up to $1 \%$ ) in some European populations [20], and the corresponding knock-in animals develop an age and gene dosage-dependent hypertrophic cardiomyopathy and heart failure phenotype. At the molecular level, this mutation is associated with significantly decreased MLP mRNA and protein levels. Loss of MLP has also been reported in heart failure [50], and loss of MLP-mediated signaling may contribute to the development of this condition. Furthermore, W4R-MLP is associated with loss of affinity to its binding partner telethonin and translocates from the sarcomeric Z-disc to the nucleus (for more detailed reviews on MLP, please see: [6, 10]).

Telethonin (also known as titin-cap or t-cap) is a $19-\mathrm{kDa} Z$ disc protein with a unique $\beta$-sheet structure which assembles in a palindromic way with the N-terminal portion of titin [51] and thereby may constitute a signalosome participating in the process of cardio-mechanosensing. A variety of telethonin mutations are associated with the development of congenital diseases, including limb girdle muscular dystrophy $2 \mathrm{G}[8,35$, 38], hypertrophic cardiomyopathy (HCM), DCM [4, 12, 18], and intestinal pseudo-obstruction [32].

Telethonin-deficient and transgenic animals were generated, and it was shown that this protein is not an indispensable component of the titin-anchoring system, nor is deletion of the gene or cardiac-specific overexpression associated with a spontaneous cardiac phenotype, at least in mouse. It was found that a main novel function of telethonin is to modulate the turnover of the proapoptotic tumor suppressor p53 after biomechanical stress in the nuclear compartment, thus linking telethonin directly to apoptosis - a process which may be called mechanoptosis (i.e., apoptosis after biomechanical stress or a mechanosensitive type of cell death). In addition, loss of telethonin mRNA and nuclear accumulation of this protein is associated with human heart failure, an effect which may contribute to enhanced rates of apoptosis found in these hearts [21]. Mechanoptosis may be defined as a new type of apoptosis found only in striated muscle which is (1) induced via increased mechanical stress and (2) modified by musclespecific proteins such as telethonin. However, it remains to be analyzed whether telethonin also affects other types of cell death such as necroptosis or processes such as autophagy.

These data support the concept of using antiapoptotic strategies to avoid the loss of cardiac myocytes [11]; however, using growth factor treatment as an antiapoptotic strategy in heart failure patients was not successful which possibly highlights our lack of knowledge of the underlying molecular mechanisms and hence our inability to interfere [15].

In addition to the chronic adaptive mechanisms described above, which are linked to gene expression, stretch also causes a more immediate change in actomyosin cross-bridge kinetics. It was recently shown that stretch applied to activated cardiac trabeculae is related on a millisecond timescale to a rise in force and to a decrease in Pi production and, therefore, 


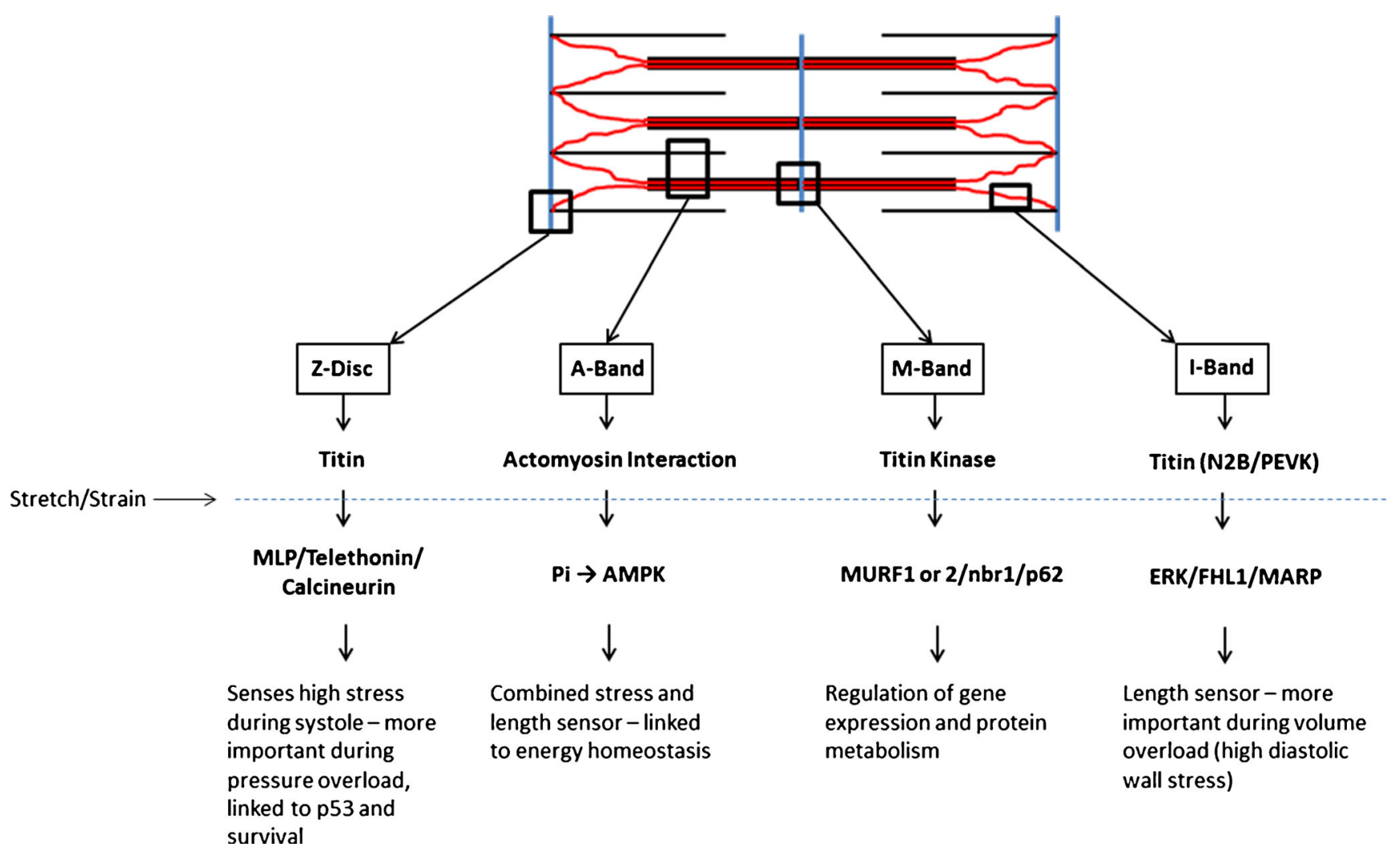

Fig. 1 Schematic representation of sarcomere-associated mechanosensory processes

decreased ATP hydrolysis, the latter lasting for the whole duration of stretch $[2,30]$. This property seems to be intrinsic to the cardiac contractile apparatus and indicates an increase in the force economy of the cross-bridges after stretch. The change in the rate of Pi release may also affect homeostasis of cellular energy metabolism through Pi feedback pathways [45], which may be sensed by the adenosine monophosphate kinase (AMPK), an enzyme already implicated in mechanosensation - at least in epithelial cells [48]. In fact, AMPK is localized to the nucleus and cytoplasm [43] and, therefore, may well be able to sense changes in sarcomeric AMP/ATP ratios. Moreover, mutations in this gene are a wellknown cause of HCM [3], and AMPK activity is necessary for stress-related survival of many cell types, including tumor cells [16]. Cardiomyopathies such as HCM are often associated with increased force production, but decreased efficiency. AMPK may well be able to sense these changes and translate them into long-term effects such as hypertrophy and/or cell survival-related pathways. It would be interesting to analyze these effects in heart failure, where $\beta \mathrm{MHC}$ is upregulated and which is known to have slower ATPase activity.

\section{N2A and N2B - titin mechanosensor complexes}

With a molecular mass of up to $4.2 \mathrm{MDa}$, titin is the largest molecule in biology and well known for its multiple functions such as serving as a molecular ruler, its importance during embryonic development, and for its role in providing mechanical stability. Two isoforms of titin are found in the adult heart: the N2B and N2BA isoforms. Both isoforms contain N2B, PEVK, and multiple immunoglobulin (Ig) domains, with the N2BA isoform also containing an additional N2A domain. All of these domains unfold upon stretch and/or store energy during every cycle of contraction and relaxation via entropic springs [28].

Smaller mammals such as the rat and mouse express mainly the shorter and stiffer N2B isoform with larger mammals expressing both the $\mathrm{N} 2 \mathrm{~B}$ and the longer and more compliant N2BA isoform. During postnatal development, stiffness increases due to switching of fetal cardiac titin (a more compliant isoform) to adult N2B and N2BA isoforms. Diseases such as DCM have also been shown to affect the $\mathrm{N} 2 \mathrm{BA} / \mathrm{N} 2 \mathrm{~B}$ ratio to varying extents. An increase in titin-mediated stiffness has been observed in a tachycardia-induced DCM canine model [49], while a decrease in titin stiffness has been seen in patients with end-stage DCM, whereas an increase has been seen in patients with earlier stage disease [27]. It remains to be elucidated whether different types of pathological stimuli, species differences, early versus late effects of disease, or different diseases per se specifically modify titin-mediated stiffness.

The N2B domain binds specifically to four and a half LIM protein 1 (FHL1), which in turn is the core of a signalosome 
consisting of RAF, MEK1/2, and ERK2, thus connecting growth factor-mediated Gq signaling and extracellular signals to titin extensibility and finally to changes in gene expression. Interestingly, loss of FHL1 blunts pathologic hypertrophy, and as such, inhibition of this pathway might be beneficial [46].

Another important pathway is linked to the N2A elastic titin domain, where the muscle ankyrin repeat proteins (MARP) including cardiac ankyrin repeat protein (CARP), ankrd2/Arpp, and DARP interact to constitute a signalosome which responds to passive stretch in vitro [34].

\section{Titin kinase mechanosensor complex}

While titin's elastic I-band domains may be able to primarily sense strain and titin's Z-disc anchored amino-terminus is involved in the sensation of stress, titin also contains a kinase domain which is involved in mechanosensation. Interestingly, titin's M-line domain contains a mechanically modulated kinase able to bind and phosphorylate nbr1 and p62 in vitro. MURF1 and 2 (and probably MURF3 which has not been analyzed yet) also bind to this complex and will translocate into the nucleus upon mechanical inactivity, where they downregulate and/or induce the nuclear export of serum response factor (SRF) and, as such, aggravate the transcriptional atrophy program [5]. This is supported by the R279W-titin kinase mutation which is associated with hereditary myopathy with early respiratory failure (HMERF) and which leads to a dramatic loss of affinity to nbr1 [25]. Additional evidence for this model is supported by in vitro experiments whereby stretching of the kinase domain leads to activation of the kinase, thus effectively linking mechanosensation to kinase activity ("mechanozymatics") [42]. Moreover, titin's kinase domain is linked via nbr1 and p62 to autophagy, a process of regulated protein and organelle turnover [9].

However, the mechanism of tail release of the titin kinase remains unclear [31], HMERF patients develop primarily a skeletal muscle phenotype, and recently, mutations outside the titin kinase domain have been found to cause HMERF, which points to the presence of additional mechanisms [37, 41]. Clearly, inducible pluripotent stem cell-derived systems and essential gain and loss of function models are needed to understand the titin kinase-mediated pathways better.

\section{Summary}

Titin's N2A, N2B, and titin kinase domains may primarily function as length sensors (i.e., $\varepsilon=\Delta L / L_{0}$ ) during diastole where wall stresses are relatively low. This function is important during volume overload, which leads to the addition of sarcomeres in series. In contrast, the sarcomeric Z-disc may function as a stress sensor $(\sigma=F / A)$ particularly during systole where wall stresses are high, where sarcomeres are added in parallel, and where cell survival pathways are activated to avoid apoptosis. Other stresses such as shear stress and torque may also be sensed by the Z-disc. The known macrostructural changes of the sarcomeric Z-disc from the "basketweave" formation in systole to the "small lattice" formation in diastole may play a role here, but these conformational changes remain poorly understood [40]. Aside from that, actomyosin interaction may also link stretch to energy homeostasis (Fig. 1).

Open Access This article is distributed under the terms of the Creative Commons Attribution License which permits any use, distribution, and reproduction in any medium, provided the original author(s) and the source are credited.

\section{References}

1. Beyder A, Strege PR, Reyes S, Bernard CE, Terzic A, Makielski J, Ackerman MJ, Farrugia G (2012) Ranolazine decreases mechanosensitivity of the voltage-gated sodium ion channel $\mathrm{Na}(\mathrm{v}) 1.5$ : a novel mechanism of drug action. Circulation 125(22): 2698-2706. doi:10.1161/CIRCULATIONAHA.112.094714

2. Bickham DC, West TG, Webb MR, Woledge RC, Curtin NA, Ferenczi MA (2011) Millisecond-scale biochemical response to change in strain. Biophys J 101(10):2445-2454. doi:10.1016/j.bpj. 2011.10.007

3. Blair E, Redwood C, Ashrafian H, Oliveira M, Broxholme J, Kerr B, Salmon A, Ostman-Smith I, Watkins H (2001) Mutations in the gamma(2) subunit of AMP-activated protein kinase cause familial hypertrophic cardiomyopathy: evidence for the central role of energy compromise in disease pathogenesis. Hum Mol Genet 10(11):12151220

4. Bos JM, Poley RN, Ny M, Tester DJ, Xu X, Vatta M, Towbin JA, Gersh BJ, Ommen SR, Ackerman MJ (2006) Genotype-phenotype relationships involving hypertrophic cardiomyopathy-associated mutations in titin, muscle LIM protein, and telethonin. Mol Genet Metab 88(1):78-85

5. Braun T, Gautel M (2011) Transcriptional mechanisms regulating skeletal muscle differentiation, growth and homeostasis. Nat Rev Mol Cell Biol 12(6):349-361. doi:10.1038/nrm3118

6. Buyandelger B, Ng KE, Miocic S, Gunkel S, Piotrowska I, Ku CH, Knoll R (2011) Genetics of mechanosensation in the heart. J Cardiovasc Transl Res 4(3):238-244. doi:10.1007/s12265-0119262-6

7. Esposito G, Rapacciuolo A, Naga Prasad SV, Takaoka H, Thomas SA, Koch WJ, Rockman HA (2002) Genetic alterations that inhibit in vivo pressure-overload hypertrophy prevent cardiac dysfunction despite increased wall stress. Circulation 105(1):85-92

8. Ferreiro A, Mezmezian M, Olive M, Herlicoviez D, Fardeau M, Richard P, Romero NB (2011) Telethonin-deficiency initially presenting as a congenital muscular dystrophy. Neuromuscul Disord 21(6):433-438. doi:10.1016/j.nmd.2011.03.005

9. Gautel M (2011) Cytoskeletal protein kinases: titin and its relations in mechanosensing. Pflugers Arch 462(1):119-134. doi:10.1007/ s00424-011-0946-1

10. Gunkel S, Heineke J, Hilfiker-Kleiner D, Knoll R (2009) MLP: a stress sensor goes nuclear. J Mol Cell Cardiol 47(4):423-425. doi:10. 1016/j.yjmcc.2009.07.012

11. Hayakawa Y, Chandra M, Miao W, Shirani J, Brown JH, Dorn GW 2nd, Armstrong RC, Kitsis RN (2003) Inhibition of cardiac myocyte 
apoptosis improves cardiac function and abolishes mortality in the peripartum cardiomyopathy of Galpha(q) transgenic mice. Circulation 108(24):3036-3041. doi:10.1161/01.CIR.0000101920. 72665.58

12. Hayashi $T$, Arimura $T$, Itoh-Satoh $M$, Ueda $K$, Hohda S, Inagaki N, Takahashi M, Hori H, Yasunami M, Koga Y, Nakamura H, Matsuzaki M, Choi BY, Bae SW, Park JE, Knöll R, Hoshijima M, Chien KR, Kimura A (2004) TCAP mutations in hypertrophic cardiomyopathy and dilated cardiomyopathy. J Am Coll Cardiol Decis 44(11):2192-2201

13. Heineke J, Wollert KC, Osinska H, Sargent MA, York AJ, Robbins J, Molkentin JD (2010) Calcineurin protects the heart in a murine model of dilated cardiomyopathy. J Mol Cell Cardiol 48(6):1080 1087. doi:10.1016/j.yjmcc.2009.10.012

14. Hershberger RE, Hedges DJ, Morales A (2013) Dilated cardiomyopathy: the complexity of a diverse genetic architecture. Nat Rev Cardiol 10(9):531-547. doi:10.1038/nrcardio.2013. 105

15. Ibe W, Saraste A, Lindemann S, Bruder S, Buerke M, Darius H, Pulkki K, Voipio-Pulkki LM (2007) Cardiomyocyte apoptosis is related to left ventricular dysfunction and remodelling in dilated cardiomyopathy, but is not affected by growth hormone treatment. Eur J Heart Fail 9(2):160-167. doi:10.1016/j.ejheart. 2006.06.002

16. Jeon S-M, Chandel NS, Hay N (2012) AMPK regulates NADPH homeostasis to promote tumour cell survival during energy stress. Nature 485:661-667

17. Knöll R, Hoshijima M, Chien K (2003) Cardiac mechanotransduction and implications for heart disease. $\mathrm{J}$ Mol Med Dec 81(12):750-756

18. Knöll R, Hoshijima M, Hoffman HM, Person V, Lorenzen-Schmidt I, Bang ML, Hayashi T, Shiga N, Yasukawa H, Schaper W, McKenna W, Yokoyama M, Schork NJ, Omens JH, McCulloch AD, Kimura A, Gregorio CC, Poller W, Schaper J, Schultheiss HP, Chien KR (2002) The cardiac mechanical stretch sensor machinery involves a $Z$ disc complex that is defective in a subset of human dilated cardiomyopathy. Cell 111(7):943-955

19. Knöll R, Iaccarino G, Tarone G, Hilfiker-Kleiner D, Bauersachs J, Leite-Moreira AF, Sugden PH, Balligand JL (2011) Towards a redefinition of 'cardiac hypertrophy' through a rational characterization of left ventricular phenotypes: a position paper of the Working Group 'Myocardial Function' of the ESC. Eur J Heart Fail 13(8):811-819. doi:10.1093/eurjhf/hfr071

20. Knöll R, Kostin S, Klede S, Savvatis K, Klinge L, Stehle I, Gunkel S, Kotter S, Babicz K, Sohns M, Miocic S, Didie M, Knoll G, Zimmermann WH, Thelen P, Bickeboller H, Maier LS, Schaper W, Schaper J, Kraft T, Tschope C, Linke WA, Chien KR (2010) A common MLP (muscle LIM protein) variant is associated with cardiomyopathy. Circ Res 106(4):695-704. doi:10.1161/ CIRCRESAHA.109.206243

21. Knöll R, Linke WA, Zou P, Miocic S, Kostin S, Buyandelger B, Ku CH, Neef S, Bug M, Schafer K, Knoll G, Felkin LE, Wessels J, Toischer K, Hagn F, Kessler H, Didie M, Quentin T, Maier LS, Teucher N, Unsold B, Schmidt A, Birks EJ, Gunkel S, Lang P, Granzier H, Zimmermann WH, Field LJ, Faulkner G, Dobbelstein M, Barton PJ, Sattler M, Wilmanns M, Chien KR (2011) Telethonin deficiency is associated with maladaptation to biomechanical stress in the mammalian heart. Circ Res 109(7):758-769. doi:10.1161/ CIRCRESAHA.111.245787

22. Knöll R, Marston S (2012) On mechanosensation, acto/myosin interaction, and hypertrophy. Trends Cardiovasc Med 22(1):17-22. doi:10.1016/j.tcm.2012.06.005

23. Kung C (2005) A possible unifying principle for mechanosensation. Nature 436(7051):647-654. doi:10.1038/nature03896

24. Kuwahara K, Wang Y, McAnally J, Richardson JA, Bassel-Duby R, Hill JA, Olson EN (2006) TRPC6 fulfills a calcineurin signaling circuit during pathologic cardiac remodeling. J Clin Invest 116(12): 3114-3126. doi:10.1172/JCI27702

25. Lange S, Xiang F, Yakovenko A, Vihola A, Hackman P, Rostkova E, Kristensen J, Brandmeier B, Franzen G, Hedberg B, Gunnarsson LG, Hughes SM, Marchand S, Sejersen T, Richard I, Edstrom L, Ehler E, Udd B, Gautel M (2005) The kinase domain of titin controls muscle gene expression and protein turnover. Science 308(5728):1599-1603

26. Laslett LJ, Alagona P Jr, Clark BA 3rd, Drozda JP Jr, Saldivar F, Wilson SR, Poe C, Hart M (2012) The worldwide environment of cardiovascular disease: prevalence, diagnosis, therapy, and policy issues: a report from the American College of Cardiology. J Am Coll Cardiol 60(25 Suppl):S1-49. doi:10. 1016/j.jacc.2012.11.002

27. LeWinter MM, Granzier H (2010) Cardiac titin: a multifunctional giant. Circulation 121(19):2137-2145. doi:10.1161/ CIRCULATIONAHA.109.860171

28. Linke WA, Grutzner A (2008) Pulling single molecules of titin by AFM - recent advances and physiological implications. Pflugers Arch 456(1):101-115. doi:10.1007/s00424-007-0389-x

29. Maillet M, van Berlo JH, Molkentin JD (2013) Molecular basis of physiological heart growth: fundamental concepts and new players. Nat Rev Mol Cell Biol 14(1):38-48. doi:10.1038/nrm3495

30. Mansfield C, West TG, Curtin NA, Ferenczi MA (2012) Stretch of contracting cardiac muscle abruptly decreases the rate of phosphate release at high and low calcium. J Biol Chem 287(31):25696-25705. doi:10.1074/jbc.M112.373498

31. Mayans O, Benian GM, Simkovic F, Rigden DJ (2013) Mechanistic and functional diversity in the mechanosensory kinases of the titinlike family. Biochem Soc Trans 41(4):1066-1071. doi:10.1042/ BST20130085

32. Mazzone A, Strege PR, Tester DJ, Bernard CE, Faulkner G, Degiorgio R, Makielski JC, Stanghellini V, Gibbons SJ, Ackerman MJ, Farrugia G (2008) A mutation in telethonin alters Nav1.5 function. J Biol Chem 283(24):16537-16544

33. Mercola M, Ruiz-Lozano P, Schneider MD (2011) Cardiac muscle regeneration: lessons from development. Genes Dev 25(4):299-309. doi:10.1101/gad.2018411

34. Miller MK, Bang ML, Witt CC, Labeit D, Trombitas C, Watanabe K, Granzier H, McElhinny AS, Gregorio CC, Labeit S (2003) The muscle ankyrin repeat proteins: CARP, ankrd2/Arpp and DARP as a family of titin filament-based stress response molecules. J Mol Biol 333(5):951-964

35. Moreira ES, Wiltshire TJ, Faulkner G, Nilforoushan A, Vainzof M, Suzuki OT, Valle G, Reeves R, Zatz M, Passos-Bueno MR, Jenne DE (2000) Limb-girdle muscular dystrophy type $2 \mathrm{G}$ is caused by mutations in the gene encoding the sarcomeric protein telethonin. Nat Genet 24(2):163-166

36. Mosca SM (2007) Cardioprotective effects of stretch are mediated by activation of sarcolemmal, not mitochondrial, ATP-sensitive potassium channels. Am J Physiol Heart Circ Physiol 293(2):H1007-1012. doi:10.1152/ajpheart.00051.2007

37. Ohlsson M, Hedberg C, Bradvik B, Lindberg C, Tajsharghi H, Danielsson O, Melberg A, Udd B, Martinsson T, Oldfors A (2012) Hereditary myopathy with early respiratory failure associated with a mutation in A-band titin. Brain 135(Pt 6):1682-1694. doi:10.1093/ brain/aws 103

38. Olive M, Shatunov A, Gonzalez L, Carmona O, Moreno D, Quereda LG, Martinez-Matos JA, Goldfarb LG, Ferrer I (2008) Transcriptionterminating mutation in telethonin causing autosomal recessive muscular dystrophy type $2 \mathrm{G}$ in a European patient. Neuromuscul Disord 18(12):929-933. doi:10.1016/j.nmd.2008.07.009

39. Ovize M, Kloner RA, Przyklenk K (1994) Stretch preconditions canine myocardium. Am J Physiol 266(1 Pt 2):H137-146

40. Perz-Edwards RJ, Reedy MK (2011) Electron microscopy and X-ray diffraction evidence for two Z-band structural states. Biophys $\mathrm{J}$ 101(3):709-717. doi:10.1016/j.bpj.2011.06.024 
41. Pfeffer G, Elliott HR, Griffin H, Barresi R, Miller J, Marsh J, Evila A, Vihola A, Hackman P, Straub V, Dick DJ, Horvath R, SantibanezKoref M, Udd B, Chinnery PF (2012) Titin mutation segregates with hereditary myopathy with early respiratory failure. Brain 135(Pt 6): 1695-1713. doi:10.1093/brain/aws102

42. Puchner EM, Alexandrovich A, Kho AL, Hensen U, Schafer LV, Brandmeier B, Grater F, Grubmuller H, Gaub HE, Gautel M (2008) Mechanoenzymatics of titin kinase. Proc Natl Acad Sci U S A 105(36):13385-13390. doi:10.1073/pnas.0805034105

43. Salt I, Celler JW, Hawley SA, Prescott A, Woods A, Carling D, Hardie DG (1998) AMP-activated protein kinase: greater AMP dependence, and preferential nuclear localization, of complexes containing the alpha2 isoform. Biochem J 334(Pt 1):177-187

44. Sasano T, McDonald AD, Kikuchi K, Donahue JK (2006) Molecular ablation of ventricular tachycardia after myocardial infarction. Nat Med 12(11):1256-1258. doi:10.1038/nm1503

45. Schmitz JP, Jeneson JA, van Oorschot JW, Prompers JJ, Nicolay K, Hilbers PA, van Riel NA (2012) Prediction of muscle energy states at low metabolic rates requires feedback control of mitochondrial respiratory chain activity by inorganic phosphate. PLoS One 7(3):e34118. doi:10.1371/journal.pone.0034118

46. Sheikh F, Raskin A, Chu PH, Lange S, Domenighetti AA, Zheng M, Liang X, Zhang T, Yajima T, Gu Y, Dalton ND,
Mahata SK, Dorn GW 2nd, Heller-Brown J, Peterson KL, Omens JH, McCulloch AD, Chen J (2008) An FHL1containing complex within the cardiomyocyte sarcomere mediates hypertrophic biomechanical stress responses in mice. J Clin Invest 118(12):3870-3880

47. Takahashi K, Kakimoto Y, Toda K, Naruse K (2013) Mechanobiology in cardiac physiology and diseases. J Cell Mol Med 17(2):225-232. doi:10.1111/jcmm.12027

48. Takawira D, Budinger GR, Hopkinson SB, Jones JC (2011) A dystroglycan/plectin scaffold mediates mechanical pathway bifurcation in lung epithelial cells. J Biol Chem 286(8):6301-6310. doi:10. 1074/jbc.M110.178988

49. Wu Y, Bell SP, Trombitas K, Witt CC, Labeit S, LeWinter MM, Granzier H (2002) Changes in titin isoform expression in pacinginduced cardiac failure give rise to increased passive muscle stiffness. Circulation 106(11):1384-1389

50. Zolk O, Caroni P, Bohm M (2000) Decreased expression of the cardiac LIM domain protein MLP in chronic human heart failure. Circulation 101(23):2674-2677

51. Zou P, Pinotsis N, Lange S, Song YH, Popov A, Mavridis I, Mayans OM, Gautel M, Wilmanns M (2006) Palindromic assembly of the giant muscle protein titin in the sarcomeric Z-disk. Nature 439(7073): $229-233$ 